\title{
Open Globe Injury in Children
}

\author{
(1) Sevinç Şahin Atik \\ Katip Çelebi University Atatürk Training and Research Hospital, Clinic of Opthalmology, İzmir, Turkey
}

\begin{abstract}
Aim: To evaluate retrospectively the epidemiologic data and outcomes of pediatric open globe injury (OGI).

Materials and Methods: The medical records of all pediatric cases ( $<16$ years old) diagnosed with OGl in İmir Katip Çelebi University Atatürk Teaching and Research Hospital, Clinic of Ophthalmology between January 2009 and December 2018 were screened. Age, sex, history, cause of trauma, treatment received, visual acuity (VA) at presentation, and final VA were recorded.

Results: A total of 48 patients were included in this study. The mean age at the time of injury was $10.72 \pm 4.74$ years, ranging from 1 to 16 years. Game-related accidents were the most common cause of all pediatric OGI patients with a frequency of $58.3 \%$ ( $n=28$ ). Of the OGls $56.3 \%$ $(n=27)$ were in zone I, followed by zone II $(39.5 \% ; n=19)$, and zone III $(4.2 \% ; n=2)$. Patients with vitreous hemorrhage or retinal detachment at admission were found to have a higher risk of poor prognosis. The principal predictor for a good visual outcome was found to be initial bestcorrected VA over 20/200.
\end{abstract}

Conclusion: To predict the prognosis in the best way, every patient with OGI should be carefully evaluated both at the time of admission and during the follow-up period.

Keywords: Children, open globe injury, trauma, visual acuity

\section{Introduction}

Open globe injury (OGI) is defined as the complete laceration of the cornea or sclera, depending on trauma or other condition. It is one of the main causes of preventable monocular blindness in childhood. Despite the many important developments in ophthalmic surgery, the complete visual recovery after an OGI is almost impossible and OGIs often cause permanent visual loss. In underdeveloped and developing countries, the incidence of OGI in children is higher $(1,2)$.

In this study, we aim to evaluate the visual outcome of OGI in pediatric cases and to analyze the epidemiologic data retrospectively.

\section{Materials and Methods}

After obtaining informed consent from patients and their families, the medical records of all patients aged 16 years or younger at the time of injury diagnosed with OGI in İzmir Katip Çelebi University Atatürk Teaching and Research Hospital, Clinic of Ophthalmology between January 2009 and December 2018 were retrospectively analyzed.

Demographic features including age, gender, cause and place of injury, date of injury, and eyes involved, were evaluated based on the clinical records. Initial visual acuity (VA), zone of injury, clinical signs, and associated features (hyphemia, lens injury, endophthalmitis, retinal detachment, laceration of eyelid/eyebrow, and vitreous hemorrhage) were recorded. Management, follow-up data including need for 
additional surgery, and the final VA were noted.

The zone of injury was defined by the location of the globe opening: zone I injuries were confined to the cornea and limbus, zone II involved the anterior $5 \mathrm{~mm}$ of the sclera, and zone III injuries involved full-thickness scleral defects $>5 \mathrm{~mm}$ posterior to the limbus. Initial and final VAs were classified as no light perception, light perception, hand motion, 1/200-19/200, 20/200-20/50, and $\geq 20 / 40$. According to the differences between initial and final VAs, the patients were grouped into those with or without improvement in VA.

\section{Statistical Analysis}

Statistical analysis was performed on IBM Statistical Package for Social Sciences (SPSS) software (version 22, SPSS, Inc, Chicago, IL, USA). Continuous and categorical variables were displayed as mean \pm standard deviation and percentages, respectively. The student's t-test was used to assess the differences between means. Differences between categorical variables were analyzed by chi-square test and the analysis of variance for continuous variables. $P$ values $<0.05$ were considered to be statistically significant.

\section{Results}

A total of 48 patients, diagnosed with OGI, were included in the study. The mean age at the time of injury was $10.72 \pm 4.74$ years, ranging from 1 to 16 years. This was $10.57 \pm 4.73$ years for boys and $11.15 \pm 4.95$ years for girls. Thirty-five of the cases were male $(72.9 \%)$. Of the patients with OGI, 18 (37.5\%) involved the right eye, and 30 (62.5\%) involved the left eye.

Game-related accidents were the most common causes of all pediatric OGl patients with a frequency of $58.3 \%$ $(n=28)$. Injuries resulted from home accidents in $18.7 \%$ $(n=9)$, traffic accidents in $8.3 \%(n=4)$, work accidents in $6.2 \%(n=3)$, fighting in $6.2 \%(n=3)$ and falls in $2 \%(n=1)$. Of all cases, $91.6 \%(n=44)$ were admitted to our hospital within the first 24 hours of injury. Of the OGls, 56.3\% ( $n=27)$ were in zone I, followed by zone II (39.5\%; $n=19)$, and zone III $(4.2 \% ; n=2)$. Injuries were most often caused by glass $(29.2 \% ; n=14)$, wood $(18.8 \% ; n=9)$, pencils $(8.3 \% ; n=4)$, and knives $(6,3 \% ; n=3)$.

Hyphemia and iris prolapses were the most common signs on admission (58.3\%, $\mathrm{n}=28$ and $58.3 \%, \mathrm{n}=28$, respectively), followed by vitreous hemorrhage ( $25 \% ; n=12)$, laceration on eyelid and/or eyebrow $(16.7 \% ; n=8)$, and retinal detachment $(10.4 \% ; n=5)$.

The mean follow-up time of the patients $(n=48)$ was
232.37 days (median: 90 days; min 1- max 1.710 days). Traumatic cataract was noted in $39.6 \%(n=19)$ of cases during the follow-up period. No intraocular foreign bodies were detected in our cohort. In 3 eyes (6.3\%), phthisis bulbi was noted. Nine patients $(18.7 \%)$ required an additional operation after the primary repair.

The initial and final best-corrected visual acuity (BCVA) could be measured in 46 of 48 patients. The association between initial BCVA and final visual outcome is shown in Table 1. Patients with vitreous hemorrhage or retinal detachment at admission were found to have a higher risk of poor prognosis (Table 1).

\section{Discussion}

Disintegrity of the eye globe after a trauma is known as OGI. Rapid diagnosis and referral to a specialist for OGI is essential to improve the prognosis of the affected eye. This is also important for the pediatric age group. The overall incidence of OGI has been reported to be 2.8 to 3.9 per 100,000 (1,3-5). There are a few studies that report the incidence of pediatric OGIs in the literature. Batur et al. (1) reported that the annual incidence rates of $\mathrm{OGI}$ in the pediatric population was 5.16 per 100,000.

The incidence of OGls in pediatric ages is generally reported to range from 6.6 years to 11.6 years. In our study, it was found to be 10.72 years. There was no statistically significant difference in mean age between girls and boys. In the literature, it was reported that boys were more susceptible to OGI than girls (1). The ratio of boys to girls with OGI ranges from 1.66:1 to 5.25:1. In accordance with this data, $72.9 \%$ of the cases were male in this study and the ratio of boys to girls was 2.69:1.

It was also reported that game-related accidents were the most common cause of pediatric OGIs. Consistent with the literature, in $58.3 \%$ of cases, game-related accidents were found to be responsible for the OGI in our study (6-9). The most common causative objects of the injuries were glass and pencil in this study. Both objects causing OGls cumulatively accounted for $48 \%$ of all cases. Although some previous studies have reported similar results about causative objects (8), many of them have determined that knives and scissors were responsible for most cases $(6,10,11)$.

The results of the studies regarding which eye is more commonly affected in OGIs suggests that pediatric OGI affects both eyes at similar rates $(1,7,8,12,13)$. In our study, we showed only a slight difference between the right and left eyes. The left eye was more commonly affected than the right eye. 


\begin{tabular}{|c|c|c|c|c|}
\hline \multirow{2}{*}{\multicolumn{2}{|c|}{$<20 / 200$}} & \multicolumn{3}{|l|}{ Final visual outcome } \\
\hline & & & $\geq 20 / 200$ & $\mathbf{p}$ \\
\hline \multirow{2}{*}{ Initial VA } & $<20 / 200(n=15)$ & 11 & 4 & \multirow[t]{2}{*}{$<0.001$} \\
\hline & $\geq 20 / 200(n=32)$ & 4 & 28 & \\
\hline Ocular findings & & $\begin{array}{l}\text { No improvement in VA } \\
(n=15)\end{array}$ & $\begin{array}{l}\text { Improvement in VA } \\
(n=32)\end{array}$ & $\mathbf{p}$ \\
\hline \multirow{2}{*}{ Iris prolapses } & Yes & 8 & 20 & \multirow{2}{*}{0.751} \\
\hline & No & 7 & 12 & \\
\hline \multirow{2}{*}{ Hyphemia } & Yes & 9 & 19 & \multirow{2}{*}{1.000} \\
\hline & No & 6 & 13 & \\
\hline \multirow{2}{*}{ Traumatic cataract } & Yes & 8 & 10 & \multirow{2}{*}{0.201} \\
\hline & No & 7 & 22 & \\
\hline \multirow{2}{*}{ Vitreous hemorrhage } & Yes & 8 & 4 & \multirow{2}{*}{0.009} \\
\hline & No & 7 & 28 & \\
\hline \multirow{2}{*}{ Retinal detachment } & Yes & 5 & 0 & \multirow{2}{*}{0.002} \\
\hline & No & 10 & 32 & \\
\hline \multirow{2}{*}{ Laceration on eyelid and/or eyebrow } & Yes & 5 & 3 & \multirow{2}{*}{0.056} \\
\hline & No & 10 & 29 & \\
\hline \multirow{3}{*}{ Zone of injury } & 1 & 6 & 20 & \multirow{3}{*}{0.056} \\
\hline & II & 7 & 12 & \\
\hline & III & 2 & 0 & \\
\hline
\end{tabular}

Despite significant advances in microsurgery, pediatric OGl continues to cause visual morbidity. After an OGl, $30.4 \%$ of pediatric cases in this study were found to have a poor visual outcome. The main goal of this study was to define the factors that determine the final VA in pediatric patients with OGls. The effects of all parameters evaluated in this study on prognosis were statistically analyzed. The principal predictor for a good visual outcome was found to be initial BCVA over 20/200. Vitreous hemorrhage and retinal detachment were also predictors of a poor visual outcome (Table 1). Lesniak et al. (6) reported that the presenting VA is the best predictor of final vision, which is consistent with our study.

In 2002, Kuhn et al. (14) developed an Ocular Trauma score (OTS). They suggested that final VA could be predicted using clinical features such as initial VA, the presence of globe rupture or perforating injury, endophthalmitis, retinal detachment, and/or relative afferent pupillary defect. However, Pediatric OTS was then developed because it was difficult to evaluate the afferent pupil defect in children (15).
As one of the limitations of our study, we did not calculate OTS in our cohort.

In conclusion, here we report some clinical features and their indicating potential on visual outcome after an OGI in pediatric patients. To predict the prognosis most effectively, every patient with OGI should be carefully evaluated both at the time of admission and during the follow-up period. Appropriate safety measures and adult supervision may be recommended to reduce the incidence of ocular trauma in children.

Ethics

Ethics Committee Approval: Ethics committee approval was received.

Inform Consent: Retrospective stıudy.

Peer-review: Externally peer-reviewed.

Financial Disclosure: This research received no specific grant from any funding agency, commercial or not-forprofit sectors. 


\section{References}

1. Batur M, Seven E, Akaltun MN, Tekin S, Yasar T. Epidemiology of Open Globe Injury in Children. J Craniofac Surg 2017;28:1976-81.

2. Sahin Atik S, Ugurlu S, Egrilmez ED. Open Globe Injury: Demographic and Clinical Features. J Craniofac Surg 2018;29:62831.

3. Knyazer B, Bilenko N, Levy J, et al. Open globe eye injury characteristics and prognostic factors in southern Israel: a retrospective epidemiologic review of 10 years experience. Isr Med Assoc / 2013;15:158-62.

4. Schrader WF. Open globe injuries: epidemiological study of two eye clinics in Germany, 1981-1999. Croat Med I 2004;45:268-74.

5. Casson RJ, Walker JC, Newland HS. Four-year review of open eye injuries at the Royal Adelaide Hospital. Clin Exp Ophthalmol 2002;30:15-8.

6. Lesniak SP, Bauza A, Son JH, et al. Twelve-year review of pediatric traumatic open globe injuries in an urban U.S. population. Pediatr Ophthalmol Strabismus 2012;49:73-9.

7. Choovuthayakorn I, Patikulsila P, Patikulsila D, Watanachai N, Pimolrat W. Characteristics and outcomes of pediatric open globe injury. Int Ophthalmol 2014;34:839-44.

8. Behbehani AM, Lotfy N, Ezzdean H, Albader S, Kamel M, Abul $\mathrm{N}$. Open eye injuries in the pediatric population in Kuwait. Med Princ Pract 2002;11:183-9.
9. Schörkhuber MM, Schneider MR, Riedl R, Wackernagel $W$, Brandner $M$, Wedrich $A$. Gender differences in open globe injuries in children. Spektrum Augenheilkd 2013;27:305-10.

10. Sari A, Adiguzel $U$, Dinc $E$, et al. Epidemiologic evaluation of childhood penetrating eye injuries. Turk J Ophthalmol 2008;38:504-9.

11. Soylu M, Demircan N, Yalaz M, Işigüzel I. Etiology of pediatric perforating eye injuries in southern Turkey. Ophthalmic Epidemiol 1998;5:7-12.

12. Lee $C-H$, Lee L, Kao L-Y, Lin K-K, Yang M-L. Prognostic indicators of open globe injuries in children. Am J Emerg Med 2009;27:5305.

13. Bunting $H$, Stephens $D$, Mireskandari K. Prediction of visual outcomes after open globe injury in children: a 17-year Canadian experience. I AAPOS 2013;17:43-8.

14. Kuhn F, Maisiak R, Mann L, Mester V, Morris R, Witherspoon CD. The ocular trauma score (OTS). Ophthalmol Clin North Am 2002;15:163-5, vi.

15. Schörkhuber MM, Wackernagel W, Riedl R, Schneider MR, Wedrich A. Ocular trauma scores in paediatric open globe injuries. Br J Ophthalmol 2014;98:664-8. 